\title{
Observations of Three Species of Captive Keelbacks (Fowlea piscator, Atretium schistosum, and Amphiesma stolatum) (Natricidae)
}

\author{
Janani Narayanan ${ }^{1}$, Shakila G. Lakshmanan ${ }^{2}$, and Aarthi Murugavel ${ }^{3}$ \\ ${ }^{1}$ No:12 6th Street, 1st cross, V G Rao Nagar, C-Sector, Katpadi, Vellore, India (jananikpd@gmail.com) \\ ${ }^{2}$ Department of Advanced Zoology and Biotechnology, Ethiraj College for Women, Chennai, India (drshaki24@gmail.com) \\ ${ }^{3}$ No: 1455 T.N.H.B, Ayapakkam, Chennai, India (aarthi.4496@gmail.com)
}

Photographs by the senior author.

$\mathrm{I}$

n order to successfully maintain or even conserve a species in captivity, we must have a thorough knowledge of its behavioral ecology and habitat associations. In India, such studies often focus on birds and mammals. Little work has been conducted on reptiles, especially snakes.

Snakes occupy a wide range of habitats. Habitat selection is influenced by the presence of water (Whitaker and Shine 2002), chemical cues from prey or predators (David 2000), the physical arrangement of structural objects (Plumer 1981; Burger and Zappalorti 1988; McCoy and Bell 1991), and thermoregulatory requirements (Moore and Gillingham 2006). Because snakes often are difficult to study in nature due to their highly secretive habits and a tendency to take flight in response to the slightest disturbance, captivity can provide opportunities for studying some aspects of behavior and habitat use. Herein we present information on the habitat use by three species of captive keelbacks.

We conducted our study during the period of 2 September to 2 November 2019 in the Chennai Snake Park, Guindy, Chennai, Tamil Nadu 600022, India. During three two-hour periods (morning: 0930-1130 h; midday: 1200 $1400 \mathrm{~h}$; afternoon $1430-1630 \mathrm{~h}$ ) on 30 days for a total of 180 $\mathrm{h}$, we observed the diurnal activities of keelback snakes using the time-constrained behavioral sampling method (Martin et al. 1993; Lehner 1996).

Focal species.-Checkered Keelbacks (Fowlea piscator, Fig. 1), average total length $-1.75 \mathrm{~m}$, are one of the most abundant species of snakes in India. They are active by day and night; live in the vicinity of freshwater; and young feed on frog eggs, tadpoles, and aquatic insects, whereas adults feed on fish, frogs,
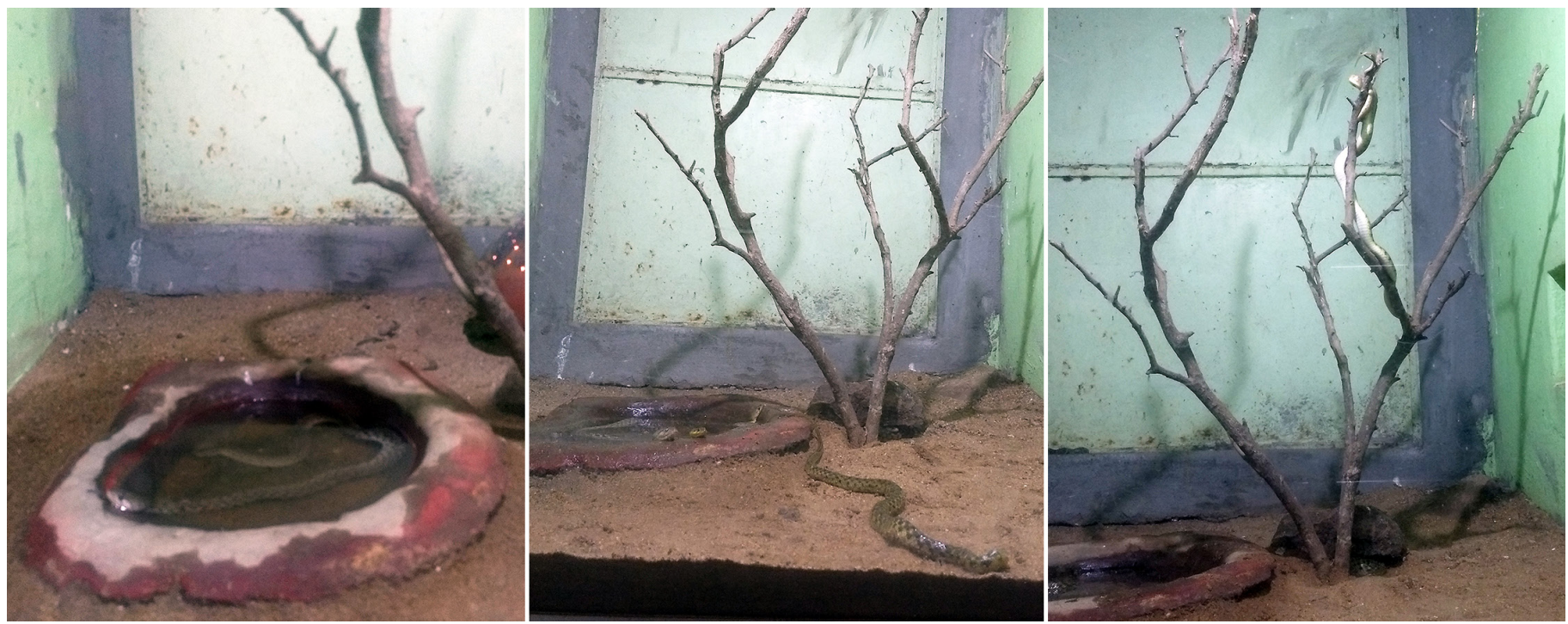

Fig. 1. Captive Checkered Keelbacks (Fowlea piscator) in water (left, center), on sand (center), and on a branch (right) in the Chennai Snake Park, Guindy, Chennai, Tamil Nadu, India. 


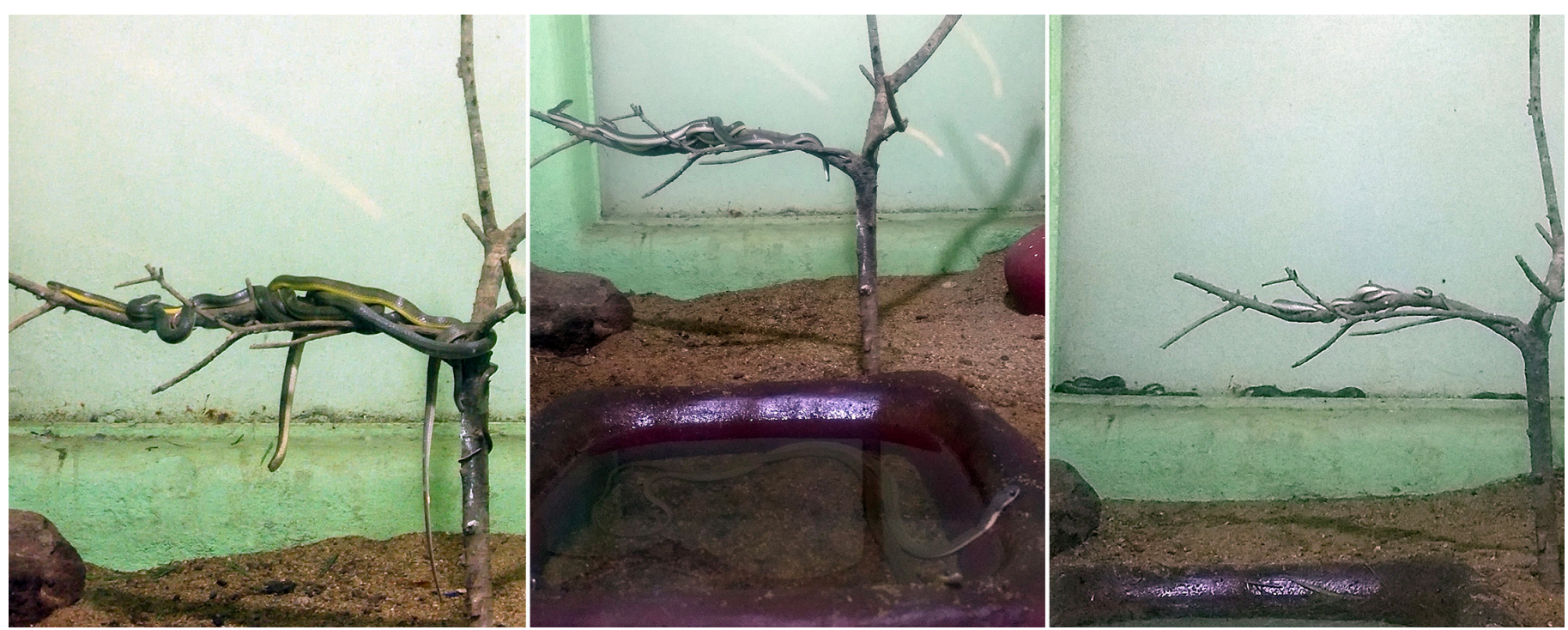

Fig. 2. Captive Olive Keelbacks (Atretium schistosum) on a branch (left, center, right), in water (center), and on the wall (right) in the Chennai Snake Park, Guindy, Chennai, Tamil Nadu, India.
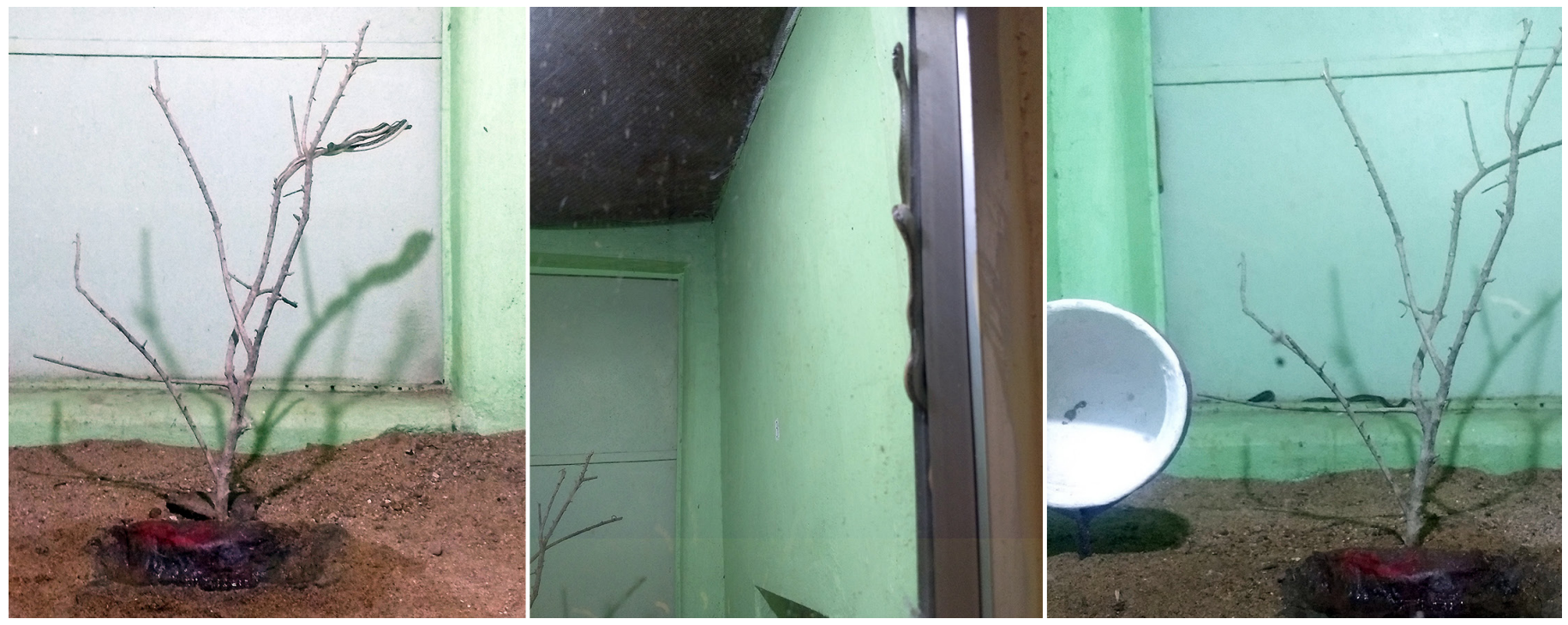

Fig. 3. Captive Striped Keelbacks (Amphiesma stolatum) snake on a branch (left), on the glass (center), and on the wall (right) in the Chennai Snake Park, Guindy, Chennai, Tamil Nadu, India.

and sometimes rodents and birds (Daniel 2002; Das 2002; Whitaker and Captain 2004). Olive Keelbacks (Atretium schistosum; Fig. 2) have an average total length of $-870 \mathrm{~cm}$, are active by day, usually are found in water or nearby vegetation, and feed on frogs, fish, and crabs (Daniel 2002; Das 2002; Whitaker and Captain 2004). Striped Keelbacks (Amphiesma stolatum; Fig. 3) have an average total length of $-80 \mathrm{~cm}$ and are diurnal but sometimes extend activity into the evening when hunting prey; they occur in grasslands, rice fields, marshy areas, and lowland forests, often along the banks of rivers (Daniel 2002; Das 2002; Whitaker and Captain 2004).

Enclosures.-Four Checkered Keelbacks, six Olive Keelbacks, and four Striped Keelbacks were housed in separate glass-fronted enclosures measuring about $1.2 \times 1.8 \times 1.2$ m. Enclosures had sand substrates and were provided with plants and branches, rocks, and shelter pots, a water dish, and a heating bulb over a basking spot. Temperatures were 27.2$35.3{ }^{\circ} \mathrm{C}$ in the sun and $20.0-33.5^{\circ} \mathrm{C}$ in the shade. Relative humidity was $40-94 \%$ in the sun and $45-97 \%$ in the shade.

Observations.-Observations were conducted from a distance of $1 \mathrm{~m}$ from the glass front of the enclosures. Using stopwatches, we recorded the durations of substrates used by snakes and activities in which they were engaged. Substrates were water, sand, branch, wall, and glass (Figs. 1-3). Activities recorded to the nearest $0.01 \mathrm{sec}$ were categorized as locomotion (movement of a snake from one location to another), swimming, climbing (ascension onto a branch or wall), burrowing (into the sandy substrate), feeding, drinking, fighting 
(attempts to displace another individual from a given location), tongue-flicking, surfacing (emergence from the water to breathe), head movement (up- and downward movement of the head), gaping, and resting. Resting was calculated by subtracting the total time devoted to any activities from the total time of observations. All are reported as the average percent or time per session.

During the morning sessions (Fig. 4), Checkered Keelbacks were most frequently in water (88.9\%), followed by sand (9.7\%) and branch $(1.7 \%)$. Olive Keelbacks were most frequently on a branch (44.8\%), followed by water (29.0\%), wall (20.7\%), and sand $(5.5 \%)$. Striped Keelbacks were most frequently on a wall (55.0\%), followed by a branch (15.5\%), glass (14.5\%), and sand (14.3\%). During the midday sessions (Fig. 1), Checkered Keelbacks were most frequently in water $(79.5 \%)$, followed by sand (16.5\%), a branch (3.0\%), and a wall (1.0\%). Olive Keelbacks were most frequently on a branch (44.0\%), followed by water $(26.5 \%)$, a wall $(24.0 \%)$, and sand $(5.5 \%)$. Striped Keelbacks were most frequently on a wall $(49.4 \%)$, followed by a branch $(17.5 \%)$, sand $(17.0 \%)$, glass $(14.6 \%)$, and water (1.5\%). During the afternoon sessions (Fig. 1), Checkered Keelbacks were most frequently in water $(75.0 \%)$, followed by sand (17.0\%), a branch (4.5\%), and a wall (3.5\%). Olive Keelbacks were most frequently on a branch (49.5\%), followed by water $(23.5 \%)$, a wall $(21.5 \%)$, and sand $(5.5 \%)$. Striped Keelbacks were most frequently on a wall $(49.5 \%)$, followed by a branch $(17.5 \%)$, sand $(16.0 \%)$, glass $(12.0 \%)$, and water $(5.0 \%)$. Durations on different substrates did not vary by time of day, with the most frequently used substrate the same for all three species during all three sessions.

During the morning sessions, Checkered Keelbacks engaged in head movement $(0.04 \mathrm{~min})$, swimming ( 1.50 $\mathrm{min})$, climbing $(0.01 \mathrm{~min})$, gaping $(0.01 \mathrm{~min})$, locomotion $(0.57 \mathrm{~min})$, and resting $(114.60 \mathrm{~min})$; Olive Keelbacks in head movement $(0.10 \mathrm{~min})$, surfacing $(0.72 \mathrm{~min})$, tongueflicking (0.14 min), swimming (1.39 min), climbing (0.60 $\mathrm{min})$, gaping $(0.01 \mathrm{~min})$, locomotion $(3.60 \mathrm{~min})$, and rest- ing (110.60 min); and Striped Keelbacks in head movement (0.08 $\mathrm{min})$, tongue-flicking $(0.28 \mathrm{~min})$, swimming $(0.01$ $\mathrm{min})$, climbing $(0.44 \mathrm{~min})$, gaping $(1.58 \mathrm{~min})$, locomotion (6.00 $\mathrm{min})$, drinking $(0.00 \mathrm{~min})$, and resting (112.60 $\mathrm{min})$. During the midday sessions, Checkered Keelbacks engaged in head movement (0.04 min), surfacing (1.01 min), swimming (0.31 min), feeding (0.60 $\mathrm{min})$, burrowing (4.50 min), climbing (0.15 min), gaping (0.01 min), locomotion (1.34 min), tongue-flicking $(0.13 \mathrm{~min})$, and resting (120.70 $\mathrm{min})$; Olive Keelbacks in head movement $(0.11 \mathrm{~min})$, surfacing $(1.50$ $\mathrm{min})$, tongue-flicking $(0.08 \mathrm{~min})$, swimming $(0.04 \mathrm{~min})$, burrowing $(8.00 \mathrm{~min})$, climbing $(0.86 \mathrm{~min})$, gaping $(0.01$ $\mathrm{min})$, locomotion $(2.11 \mathrm{~min})$, and resting (116.37 $\mathrm{min})$; and Striped Keelbacks in head movement (0.17 min), surfacing (0.01 $\mathrm{min})$, tongue-flicking $(0.35 \mathrm{~min})$, feeding $(0.16 \mathrm{~min})$, climbing (1.03 $\mathrm{min})$, locomotion $(5.38 \mathrm{~min})$, and resting (107.85 min). During the afternoon sessions, Checkered Keelbacks engaged in head movement $(0.04 \mathrm{~min})$, surfacing $(0.10 \mathrm{~min})$, tongue-flicking $(0.14 \mathrm{~min})$, swimming $(0.20$ $\mathrm{min})$, climbing $(0.65 \mathrm{~min})$, gaping (0.04 $\mathrm{min})$, locomotion $(2.10 \mathrm{~min})$, fighting $(0.10 \mathrm{~min})$, and resting $(116.10 \mathrm{~min})$; Olive Keelbacks in surfacing $(0.10 \mathrm{~min})$, tongue-flicking (0.17 min), swimming $(0.12 \mathrm{~min})$, feeding $(1.00 \mathrm{~min})$, climbing (0.68 $\mathrm{min})$, gaping $(0.01 \mathrm{~min})$, locomotion (4.18 min), and resting (110.70 min); and Striped Keelbacks in head movement $(0.14 \mathrm{~min})$, surfacing $(0.03 \mathrm{~min})$, tongueflicking $(0.39 \mathrm{~min})$, swimming $(0.06 \mathrm{~min})$, climbing $(0.92$ $\mathrm{min})$, gaping (0.01 $\mathrm{min})$, locomotion (12.07 min), drinking $(0.01 \mathrm{~min})$, and resting $(103.3 \mathrm{~min})$. All species spent most of their time (average $-85 \%$ ) resting.

Checkered Keelbacks spent the most time in water, and they are the most aquatic of the three species (Das and De Silva 2005). Olive Keelbacks were most frequently observed on branches. Although good swimmers found typically near water, they commonly climb into bushes or other forms of vegetation (Daniel 2002; Das and De Silva 2005). Striped Keelbacks are frequently found in fields and cultivated areas,
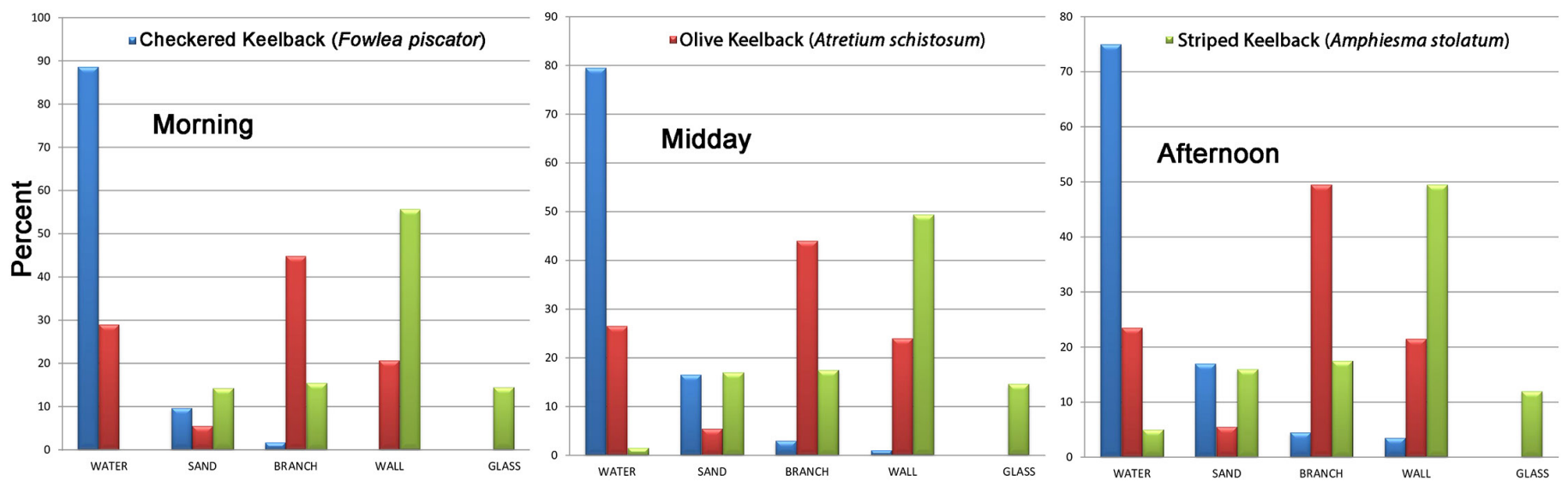

Fig. 4. Substrates used by three species of captive keelbacks (Fowlea piscator, Atretium schistosum, Amphiesma stolatum) during morning (0930-1130 h), midday (1200-1400 h), and afternoon (1430-1630 h) observation periods at the Chennai Snake Park, Guindy, Chennai, Tamil Nadu, India. 
where they often are found hiding in holes or crevices in the masonry of drains and culverts (Daniel 2002). In captivity, they were the only one of the three species to frequent gaps in the enclosure walls and under the edges of the glass. In general, the substrates most frequently chosen by each species reflect habitats exploited in nature.

\section{Acknowledgements}

We thank the Chennai Snake Park trustees, Dr. S. Paulraj, Dr. M. Arumugam, and Mr. R. Rajarathinam for their support and for providing permission to conduct our study. We also extend our thanks to Dr. S.R. Ganesh for support and guidance; without his help, this study would not have been possible.

\section{Literature Cited}

Burger, J. and R.T. Zappalorti. 1988. Habitat use in free-ranging Pine Snakes, Pituophis melanoleucus, in New Jersey Pine Barrens. Herpetologica 44: 48-55.
Daniel, J.C. 2002. The Book of Indian Reptiles and Amphibians. Bombay Natural History Society, Mumbai, India.

Das, I. 2002. A Photographic Guide to Snakes and Other Reptiles of India. New Holland Publishers Ltd., London, United Kingdom.

Das, I. and A. De Silva. 2005. A Photographic Guide to Snakes and Other Reptiles of Sri Lanka. New Holland Publishers Ltd., London, United Kingdom.

David, D.H.T. 2000. Habitat selection and prey odor in the foraging behavior of western rattlesnakes (Crotalus viridis). Behaviour 137: 119-135.

McCoy, E.D. and S.S. Bell. 1991. Habitat structure: The evolution and diversification of a complex topic, pp. 3-27. In: S.S. Bell, E.D. McCoy, and H.R. Mushinsky (eds.), Habitat Structure. Springer, Dordrecht, The Netherlands.

Moore, J.A. and J.C. Gillingham. 2006. Spatial ecology and multi-scale habitat selection by a threatened rattlesnake: The Eastern Massasauga (Sistrurus catenatus catenatus). Copeia 2006: 742-751.

Plummer, M.V. 1981. Habitat utilization, diet and movements of a temperate arboreal snake (Opheodrys aestivus). Journal of Herpetology 15: 425-432.

Whitaker, P.B. and R. Shine. 2002. Thermal biology and activity patterns of the Eastern Brownsnake (Pseudonaja textilis): A radiotelemetric study. Herpetologica 58: 436-452.

Whitaker, R. and A. Captain. 2004. Snakes of India. The Field Guide. Draco Books, Chennai, India. 